\title{
Growth, Structural, Optical and Hardness Studies of Lithium Potassium Sulphate Single Crystals- An Inorganic NLO Material
}

\author{
G. Pasupathi* , P. Philominathan \\ PG Research and Department of Physics, A. Veeriya Vandayar Memorial Sri Pushpam College, Thanjavur, India \\ Email: "gpasupathi123@gmail.com
}

Received May 25, 2012; revised June 27, 2012; accepted July 20, 2012

\begin{abstract}
Single crystal of lithium potassium sulphate, a nonlinear optical material, was grown from aqua solution by slow evaporation method at room temperature. The cell parameters were estimated by single crystal X-ray diffraction analysis. The optical transmittance of the crystal was recorded using the UV-Vis-NIR spectrophotometer and the optical band gap was calculated using this method. The second harmonic generation efficiency was measured by Kurtz and Perry powder technique and the phase-matching property was confirmed. The hardness of the material was measured by Vicker's hardness test.
\end{abstract}

Keywords: Crystal Growth; Lithium-Potassium Sulphate; Inorganic NLO Material; X-Ray Diffraction; SHG Efficiency

\section{Introduction}

In the recent past, extensive studies have been made on the synthesis and crystal growth of nonlinear optical (NLO) materials due to their potential application in the field of telecommunication, photonics and opto electronics technology. Presently, numerous inorganic NLO materials have been developed to increasing the variety of these applications by the researchers [1-3]. In this series, lithium potassium sulphate $\mathrm{LiKSO}_{4}$ (namely, LKS) belongs to a family with the general structural formula $\mathrm{M}^{\prime} \mathrm{M}^{\prime \prime} \mathrm{AX}_{4} \quad\left(\mathrm{M}^{\prime}=\mathrm{Li}, \mathrm{Na} ; \mathrm{M}^{\prime \prime}=\mathrm{K}, \mathrm{Cs}, \mathrm{Rb}\right.$ ions, $\mathrm{NH}_{4}$, $\mathrm{N}_{2} \mathrm{H}_{5}$ group and $\mathrm{AX}_{4}=\mathrm{SO}_{4}^{2-}, \mathrm{SeO}_{4}^{2-}, \mathrm{BeF}_{4}$ ). The significant attention is currently being paid to these crystals due to their physical properties such as ferroelectricity, piezoelectricity and ionic conductivity. During the past two decades, extensive studies have been carried out for the growth, structural and phase transition of LKS crystal. At room temperature, it exhibits a hexagonal system with $\mathrm{P}_{3}$ space group [4,5]. In addition, it undergoes several structural phase transitions below [6] and above room temperature [7].

In the present investigation is aimed at the growth of lithium potassium sulphate single crystals by slow evaporation method at room temperature. The grown crystals have been subjected to single crystal X-ray diffraction analysis, UV-Vis-NIR spectral analysis, optical band gap measurements, second harmonic generation (SHG) mea-

${ }^{*}$ Corresponding author. surement, phase matching and Vicker's hardness test.

\section{Experimental Procedure}

\subsection{Synthesis of the Material}

Lithium potassium sulphate was synthesized by the chemical reaction of commercially available Lithium sulphate (Analar grade-E. Merck) with Potassium sulphate (Analar grade-E. Merck) taken in the stoichiometric ratio 1:1 by dissolving double-distilled water (solvent) at room temperature and the chemical reaction is given below

$$
\mathrm{K}_{2} \mathrm{SO}_{4} \cdot \mathrm{H}_{2} \mathrm{O}+\mathrm{Li}_{2} \mathrm{SO}_{4} \rightarrow \mathrm{LiKSO}_{4} \cdot \mathrm{H}_{2} \mathrm{O}
$$

\subsection{Growth of Single Crystals}

A saturated solution of LKS was prepared by doubledistilled water. The solution was allowed to slow evaporation in the vibrational and dust free atmosphere. After the growth period of 25 days, colourless and transparent crystals were harvested. The harvested crystals were recrystallized repeatedly to achieve good quality as shown in Figure 1.

\subsection{Characterization Technique}

The single crystal $\mathrm{X}$-ray diffraction (XRD) studies of LKS were carried out using Enraf nonius CAD4 single $\mathrm{X}$-ray diffractometer with $\mathrm{MoK} \alpha(\lambda=0.717 \AA)$ radiation. The UV-Vis-NIR spectrum was recorded using Perkin elmmer Lamda 35 spectrophotometer in the range of 190 - 


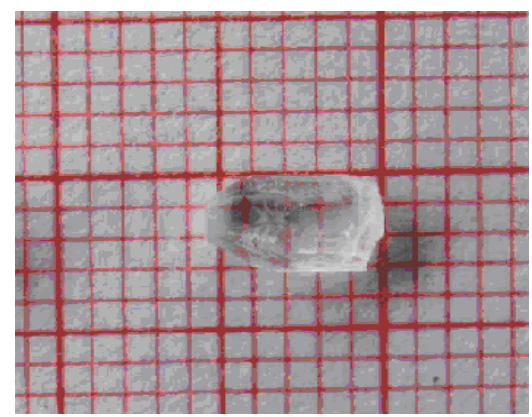

Figure 1. As the grown single crystal of lithium potassium sulphate.

$1100 \mathrm{~nm}$. The SHG efficiency and the phasematching studies were carried out by the Kurtz and Perry powder technique using a Q-switched, mode locked Nd:YAG laser. Microhardness behaviour of the grown crystal was carried out using Vicker's hardness tester.

\section{Results and Discussion}

\subsection{Structure of the Crystals}

The single crystal XRD study indicates that $\mathrm{LiKSO}_{4}$ crystallize in hexagonal system with $\mathrm{P}_{3}$ space group at room temperature. The unit cell dimensions are $\mathrm{a}=\mathrm{b}=$ 5.1453(2) $\AA$ and $c=8.6342(7) \AA$. These values are good agreement with the reported values [4]. There are two molecules in the unit cell. The structure of LKS consists of $\mathrm{Li}^{+}$and $\mathrm{SO}_{4}^{2-}$ lying on threefold axes and $\mathrm{K}^{+}$ion has a tetrahedral coordination with Li-O distances 1.909 $1.923 \AA$ Á as reported by Karpinnen et al. (Figure 2).

\subsection{Optical Transmittance Study}

The optical transmittance spectrum of LKS crystals is shown in Figure 3. The optical transmittance study may be assisted in understanding the electronic structure of the optical band gap of the crystal. The study of the absorption edge is essential in connection with the theory of electronic structure, which leads to the prediction of whether the band structure is affected near the band extreme. From the transmittance spectrum, it was observed that the grown crystals have high transmittance in the entire visible-NIR region and the lower cut-off wavelength $(253 \mathrm{~nm})$ facilitates LKS crystals to be potential nonlinear optical material for second harmonic generation of Nd:YAG laser. Using the formula,

$$
\mathrm{E}_{\mathrm{g}}=\left(\frac{\mathrm{hc}}{\lambda}\right)
$$

the value of optical band gap of LKS is calculated to be $4.24 \mathrm{eV}$. The observed behaviour of the optical spectrum and band gap value found in this work is in good agree ment with the spectrum of LKS crystal reported in literature [8].

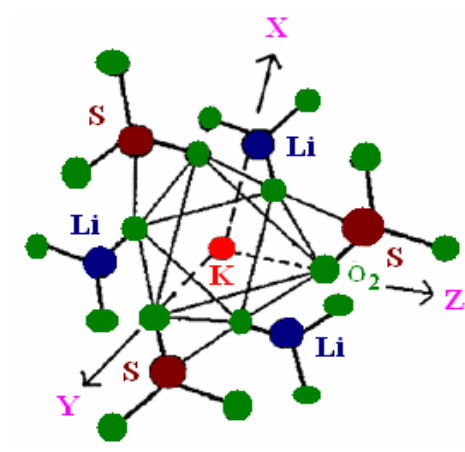

Figure 2. Coordination polyhedron of $\mathrm{K}^{+}$viewed along $\mathrm{c}-$ axis.

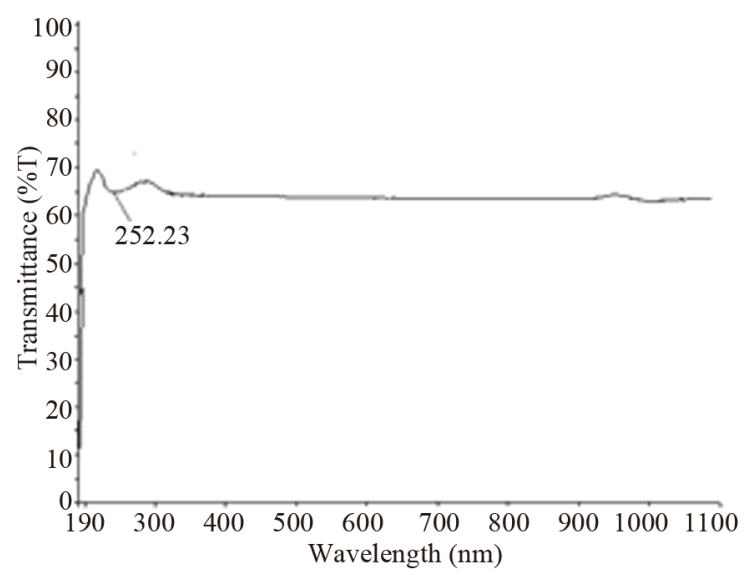

Figure 3. Optical transmittance spectrum of LKS.

\subsection{Second Harmonic Generation Measurement and Phase-Matching Studies}

The first and the most widely used technique for confirming the SHG efficiency from prospective secondorder NLO material is the Kurtz powder technique [9]. In addition to identifying the materials with non-centro symmetric crystal structure, it is also used as a screening technique to identify the materials with the capacity for phase matching. The SHG efficiency from the material is measured as a function of particle size. The continuous increase of SHG efficiency with increase of particle size and remaining essentially constant at particle sizes greater than the coherence length confirms the phase matching behavior of the material [10-12].

The powder second harmonic generation (SHG) test was carried out for LKS using Kurtz and Perry technique. Powdered sample of LKS was tightly packed in the micro capillary tubes of uniform diameter $(1.5 \mathrm{~mm})$ and irradiated by an incident laser radiation $1064 \mathrm{~nm}$ of pulse width $8 \mathrm{~ns}$ and pulse energy of $11.4 \mathrm{~mJ}$ from a Q-switched quanta ray of Nd:YAG laser. KDP was used for calibrating the SHG efficiency. The second harmonic nonlinearity of LKS was confirmed by the emission of green 
radiation $(532 \mathrm{~nm})$ by the crystal. The powder SHG efficiency of LKS was found to be 1.6 times that of the standard KDP. The measurements of SHG output at various particle size show increasing SHG intensities with increasing particle sizes (Figure 4). From this measurement, it was observed that the grown crystal proving the phase matching property.

\subsection{Microhardness Measurement}

Regarding mechanical properties, hardness testing provides useful information on the strength and deformation characteristics of the material [13] and yield stress [14]. The hardness of a material is defined as the resistance it offers to the motion of dislocations, deformations or damage under an applied stress [15]. The chemical forces in a crystal resist the motion of dislocations as it involves the displacement of atoms. This resistance is the intrinsic hardness of a crystal. As hardness properties are basically related to the crystal structure of the material, hardness studies are carried to understand the plasticity of the crystal [16].

For the static indentation test, loads varying from 25 to $200 \mathrm{~g}$ were applied on the selected faces over a fixed interval of $10 \mathrm{~s}$. The indented impressions were approximately square. For each load (P), an average of diagonal lengths (d) of the indentation mark after unloading was obtained using a calibrated micrometer attached to the eyepiece of the microscope. The Vicker's hardness number $(\mathrm{Hv})$ were calculated using the formula

$$
\mathrm{Hv}=\frac{1.8544 \mathrm{P}}{\mathrm{d}^{2}} \mathrm{~kg} / \mathrm{mm}^{2}
$$

where, $\mathrm{Hv}$ is the Vicker's microhardness number in $\mathrm{kg} / \mathrm{mm}^{2}, \mathrm{P}$ is the applied load in gm and $\mathrm{d}$ is the average diagonal length of the indentation in $\mathrm{mm}^{2}$. The plot drawn between the corresponding loads and hardness values of LKS is shown in Figure 5. Maximum indenterload applied for grown crystal was $100 \mathrm{~g}$, above this load microcracks were observed around the impression and hence readings were not taken for higher loads. From this figure, it was observed that the hardness of the title compound decreases with increase in load.

The relation between load and the size of the indentation is given by Meyer's law [14] as

$$
\mathrm{P}=\mathrm{ad}^{\mathrm{n}}
$$

where $\mathrm{a}$ is the arbitrary constant, $\mathrm{n}$ is the Meyer index (or work-hardening coefficient). Using Equations (3) and (4), we have

$$
\mathrm{Hv}=\mathrm{bP}^{(\mathrm{n}-2) / \mathrm{n}}
$$

where, $\mathrm{b}$ is a constant. The above relation indicates that Hv should increases with $P$ if $n>2$ and decrease with $P$ when $\mathrm{n}<2$. The plot $\log \mathrm{P}$ versus $\log \mathrm{d}$ is a straight line

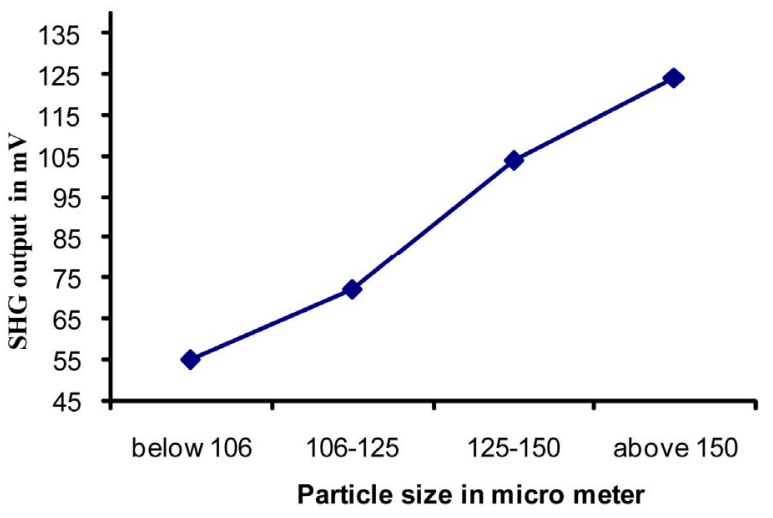

Figure 4. Phase matching curve of LKS.

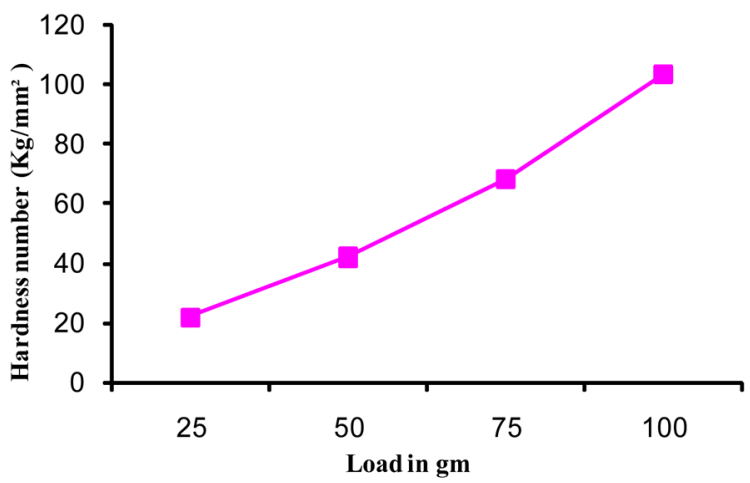

Figure 5. Hardness behaviour of LKS.

and the work hardening coefficient " $n$ " was found to be 3 - 3.6 which is greater than 2. On the basis of careful investigation on various substances, Onitsch [17] and Hanneman [18] had shown that the value of $n$ comes out to be $1-1.6$ for hard materials and more than 1.6 for soft ones. Thus the grown LKS crystal belongs to the soft material category.

\subsection{TGA/DTA Studies}

Single crystal of LKS was subjected to TGA/DTA studies. A heating rate of $20^{\circ} \mathrm{C}$ per minute was employed to melt the mixture in the ceramic $\left(\mathrm{Al}_{2} \mathrm{O}_{3}\right)$ crucible. The initial mass of the material subjected to analysis was $44.600 \mathrm{mg}$. The final mass of the residue after the analysis was $8 \%$ of the initial mass. The results of the thermal analyses are represented by the curves in Figure 6. DTA curve indicates that the grown crystal was stable upto at $260.1^{\circ} \mathrm{C}$ (melting point). The TGA curve shows the loss of weight of $61.87 \%$ at $260^{\circ} \mathrm{C}$, is may be due to liberation of volatile substances like sulfur in the compound.

\section{Conclusion}

Single crystals of lithium potassium sulphate, an inorganic nonlinear optical material, were grown by slow evaporation method at room temperature. The single crystal 


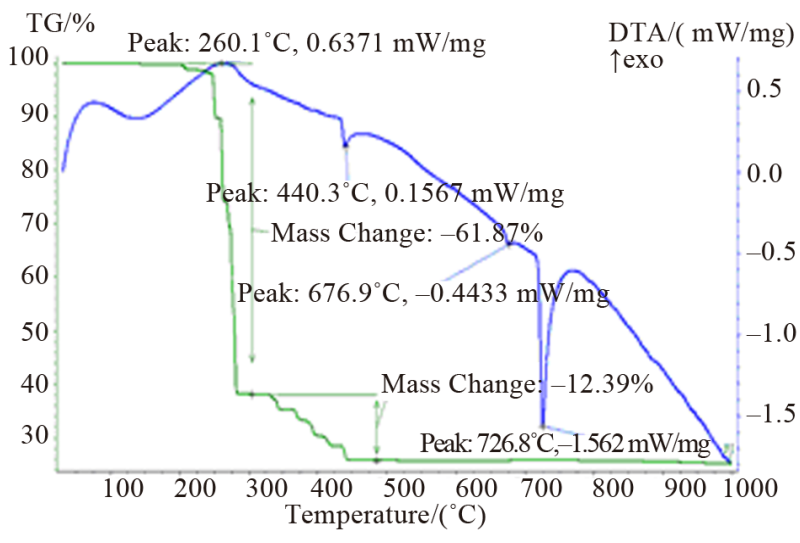

Figure 6. TG/DTA spectrum of LKS crystal.

$\mathrm{X}$-ray diffraction analysis confirms the grown crystal belongs to hexagonal system. The optical transmittance study shows the crystal has good transmittance in the entire visible-NIR region and wide band gap. The Kurtz and Perry powder SHG method confirm the SHG efficiency of LKS is 1.6 times that of KDP and phasematching property. The mechanical property of the material was studied by Vicker's hardness measurement.

\section{Acknowledgements}

One of the authors Mr. G. Pasupathi, thankful to the University Grant Commission, New Delhi for providing the funding agency through Minor Research Project.

\section{REFERENCES}

[1] K. C. Zhang and X. M. Wang, "Structure Sensitive Properties of KTP-Type Crystals," Chinese Science Bulletin, Vol. 46, No. 24, 2001, pp. 2028-2036. doi:10.1007/BF02901124

[2] S. M. Ravi Kumar, N. Melikechi, S. Selvakumar and P. Sagayaraj, "Crystal Growth and Characterization of NLO Single Crystals $\mathrm{Cd}\left(\mathrm{IO}_{3}\right)_{2}$," Journal of Crystal Growth, Vol. 311, No. 2, 2009, pp. 337-334. doi:10.1016/j.jcrysgro.2008.11.058

[3] R. Robert, C. Justin Raj, S. Krishnan and S. Jerome Das, "Growth, Theoretical and Optical Studies on Potassium Dihydrogen Orthophosphate (KDP) Single Crystals by Modified Sankaranarayanan and Ramasamy (mSR) Method," Physica B: Condensed Matter Physics, Vol. 405, No. 1, 2010, pp. 20-24.
[4] M. Karppinnen, J. O. Lundgren and R. Liminga, "Structure of Pyroelectric Lithium Potassium Sulphate, $\mathrm{LiKSO}_{4}$," Acta Crystallographica Section C, Vol. 39, 1983, pp. 3438. doi:10.1107/S0108270183003509

[5] M. A. Pimenta, S. L. V. Vierira, F. O. V. Letelier, N. L. Speziali and M. S. Dantas, "Ionic Conductivity in $\mathrm{LiK}_{0.9} \mathrm{Na}_{0.1} \mathrm{SO}_{4}$ Single Crystals," Solid State Communications, Vol. 82, No. 10, 1992, pp. 758-757. doi:10.1016/0038-1098(92)90158-6

[6] A. Lunden and J. O. Thomas, "High Conductivity Solid State Conductors: Recent Trends and Applications," World Scientific, Singapore City, 1986.

[7] H. K. Liu, M. L. Hu, W. S. Tse, D. P. Wong and S. J. Lin, "Raman Studies of Low Temperature Phase Transition in $\mathrm{LiKSO}_{4}$," Chinese Journal of Physics, Vol. 36, No. 3, 1998, pp. 542-548.

[8] A. A. El-Fadl, M. A. Gaffar and M. H. Omar, "Absorption Spectra and Optical Parameters of Lithium-Potassium Sulphate Single Crystals," Physica B, Vol. 269, No. 3-4, 1999, pp. 403-408.

[9] S. K. Kurtz and T. T. Perry, "A Second Harmonic Analyzer for the Detection of Non-Centrosymmetry," Journal of Applied Physics, Vol. 39, 1968, pp. 145-158.

[10] R. L. Sutherland, "Handbook of Nonlinear Optics," 2nd Edition, Dekker, New York, 2003.

[11] M. Kiguchi, M. Kato, M. Okunak and Y. Taniguchi, "New Method of Measuring Second Harmonic Generation Efficiecny Using Powder Crystals," Applied Physics Letters, Vol. 60, No. 16, 1992, pp. 1933-1935. doi: $10.1063 / 1.107155$

[12] A. Sonoc, M. Samoc and P. N. Prasad, "Second-Harmonic Generation in the Crystalline Complex Antimony Triiodide-Sulfur," Journal of Optical Society of Ametica $B$, Vol. 9, No. 10, 1992, pp. 1819-1824. doi:10.1364/JOSAB.9.001819

[13] B. W. Mott, "Micro-Indentation Hardness Testing," Butterworths, London, 1956.

[14] J. H. Westbrook, "Flow in Rock Salt Structure," Report 58-RL 2033 of the GE Research Laboratory, USA, 1958.

[15] N. A. Ashby, Journal of Nuclear Engineering, Vol. 6, 1951, p. 33.

[16] K. K. Rao and D. B. Sirdeshmukh, "Microhardness and Interatomic Binding in Some Cubic Crystals," Bulletin of Materials Science, Vol. 5, No. 5, 1983, pp. 449-452. doi:10.1007/BF02743923

[17] E. M. Onitsch, Mikroskopia, Vol. 2, 1947, p. 131.

[18] M. Hanneman, Metallurgia Manchu, Vol. 23, 1941, p. 135. 